\title{
Implications of the results of the WHO Study on Determinants of Outcome in Schizophrenia
}

\author{
NORMAN SARTORIUS
}

The WHO Collaborative Study on the Determinants of Outcome of Severe Mental Disorders (DOS) (Jablensky et al., 1992), Sartorius et al., 1986) was designed to investigate further some of the findings of the WHO International Pilot Study of Schizophrenia (IPSS) (WHO, 1973, 1979) which produced the unexpected finding that patients suffering from schizophrenia in the centres in developing countries appear to have a more favourable outcome at both two and five years follow-up than initially similar patients in centres in developed countries. (Leff et al., 1990a, 1992; Sartorius et al., 1987). The DOS was carried out in field centres in Aarhus (Denmark), Agra and Chandigarh (India), Cali (Columbia), Dublin (Ireland), Honolulu and Rochester (USA), Ibadan (Nigeria), Moscow (USSR), Nagasaki (Japan), Nottingham (United Kingdom), and Prague (Czechoslovakia). Six of these centres had also taken part in the IPSS.

One of the major achievements of the IPSS had been the demostration that large-scale cross-cultural studies using standardized methods of interviewing, symptom rating and diagnosis are possible. The determinants of Outcome study rested upon the same methodological foundations but used an epidemiological approach. In each of the twelve centres of the DOS, all individuals from a defined catchment area making a lifetime first contact with specified psychiatric, medical or other agencies because of symptoms of a possible schizophrenic illness were identified, assessed, and followed up for two years.

The finding of a better outcome of patients in developing countries was confirmed, as was the existence of a substantial proportion of patients (often more than half) with undoubted initial schizophrenic symptoms but a good outcome at two years. About

Indirizzo per la corrispondenza: Professor N. Sartorius, Division of Mental Health, World Health Organization, 1211 Geneva 27 (Switzerland).

Fax (+41) 22-791.0746. one third of all the patients in the study were never admitted to a psychiatric hospital, and of those that were admitted the majority were in hospital for only short periods.

The Study also produced evidence about the incidence rates of schizophrenia. Statistically significant differences were found between centres in the incidence of schizophrenia using a broad definition, although the rates ranged only from 1,5 to 4,2 per 10000 population aged $15-54$. In contrast, the incidence of schizophrenia using a narrow definition based on the presence of a limited number of «classical» symptoms in the present mental state (category $\mathrm{S}+$ of the Catego program derived from the PSE-9 interview) did not reach statistical significance of differences among centres.

This study confirms that schizophrenic illnesses are ubiquitous, appear with similar incidence in different cultures and have clinical features that are more remarkable by their similarity across cultures than by their difference (Jablensky et al., 1992). These are illnesses with variable outcomes which are more favourable in the developing countries and depend on genetic, developmental and environmental influences whose exact nature, interaction and relative importance have yet to be identified (Day et al., 1987; Katz et al., 1988; Leff et al., 1990b).

The significance of these findings rests on several facts: First, this study and its predecessor, the IPSS, opened the door to international cooperation in the study of mental disorders. Although some small-scale international studies have been carried out in the past, usually by an investigator from a developed country undertaking a study abroad, there was no certainty that large-scale investigations using standardized instruments could be successfully completed before IPSS and DOS showed how. What was particularly noteworthy was that the study centres in developed and developing countries, performed equally well and in accordance with the same research protocol. 
Second, the instruments used in this study were developed by the investigators in different countries working together. Sometimes this development began with a schedule created by one investigator and sometimes the whole work was done jointly, from the generation of items likely to be relevant in the various centres for the field tests and the analysis of the data obtained. The schedules used in the different languages were not translations: they were equivalent versions for use in different settings. The experience gained made it possible to create instruments for collaborative studies in a novel and scientifically justifiable manner (Sartorius, 1988).

Third, the finding that schizophrenic syndromes can be found in very different cultures, and that the outcome of the disorder differs among countries made an important contribution to the nature/nurture conundrum encompassing mental illness. The study confirmed that there is a universal - probably biological - basis of the sydrome and that social factors play a major role in the course of the disease and its outcome. This result indicates the need for joint research into the pathogenesis of schizophrenia by scientists from many disciplines; it also indicates the need to direct the treatment to both social and biological aspects of mental illnes in the light of the individual's experience and life pathway.

Fourth, the fact that the studies undertaken to explore reasons for the difference in outcome did not provide a precise answer to the puzzling differences demonstrated in previous studies and confirmed in this investigation underline the need for further longitudinal studies of schizophrenia in different cultures. WHO has embarked on such a study and will be coordinating the follow-up investigations involving all the centres that have participated in its work on this topic. This effort, however, has to be complemented by work on other groups of patients, if at all possible, using a prospective and comparative design.

The past two decades brought a great deal of new knowledge about schizophrenia. There is still uncertainty about the etiopathogenesis of the syndrome and about the best way to help those affected and their families. In both respects research and service can learn much from one another. WHO studies made a contribution to the resolution of the problems related to schizophrenia and should serve as a stimulus for further joint, international research and thinking about the way to provide care to those who suffer from diseases of major public health importance and to their families and communities.

\section{REFERENCES}

Day R., Nielsen J. A., Korten A., Ernberg G., Dube K. C., Gebhart J., Jablensky A., León C., Marsella A., Olatawura M., Sartorius N., Strömgren E., Takahashi R., Wig N. \& Wynne L.C. (1987). Stressful life events preceding the acute onset of schizophrenia: a cross-national study from the World Health Organization. Culture, Medicine and Psychiatry 11 (2), 123-205. Jablensky A., Sartorius N., Ernberg G., Anker M., Korten A., Cooper J. E., Day R. \& Bertelsen A. (1992). Schizophrenia: Manifestations, Incidence and Course in Different Cultures. A World Health Organization Ten-Country Study. Psychological Medicine Monograph Supplement 20, Cambridge University Press: Cambridge.

Katz M. M., Marsella A., Dube K. C., Olatawura M., Takahashi R., Nakane Y., Wynne L. C., Gift T., Brennan J., Sartorius N. \& Jablensky A. (1988). On the expression of psychosis in different cultures: schizophrenia in an Indian and in a Nigerian community: a report from the World Health Organization Project on Determinants of Outcome of Severe Mental Disorders. Culture, Medicine and Psychiatry 12, 331-355.

Leff J., Sartorius N., Jablensky A., Anker M., Korten A., Gulbinat W. \& Ernberg G. (1990a). The International Pilot Study of Schizophrenia: five-year follow-up findings. In search for the Causes of Schizophrenia, Vol. II (ed. H. Häfner and W. F. Gattaz), pp. 57-66. Springer-Verlag: Berlin.

Leff J., Wig N. N., Bedi H., Menon D. K., Kuipers L., Korten A., Ernberg G., Day R.,, Sartorius N. \& Jablensky A. (1990b). Relatives' expressed emotion and the course of schizophrenia in Chandigarh: a two-year follow-up of a first contact sample. British Journal of Psychiatry 156, 351-356.

Leff J., Sartorius N., Jablensky A., Korten A. \& Ernberg G. (1992). The International Pilot Study of Schizophrenia: five-year followup findings. Psychological Medicine 22, 131-145.

Sartorius N. (1988). Cross-cultural and international collaboration in mental health research and action: experience from the mental health programme of the World Health Organization. In Berselius Symposium XI. Transcultural Psychiatry in Stockolm, Sweden, April 8-10, 1987 (ed. B. Jansson and C. Perris). Acta Psychiatrica Scandinavica, Supplementum No. 344, vol. 78, pp. 71-74.

Sartorius N., Jablensky A., Korten A., Ernberg G., Anker M., Cooper J. E. \& Day R. (1986). Early manifestations and firstcontact incidence of schizophrenia in different cultures: a preliminary report on the initial evaluation phase of the WHO Collaborative Study on Determinants of Outcome of Severe Mental Disorder. Psychological Medicine 16, 909-928.

Sartorius N., Jablensky A., Ernberg G., Leff J., Korten A. \& Gulbinat W. (1987). Course of schizophrenia in different countries: some results of a WHO international comparative 5-year follow-up study. In Search for the Causes of Schizophrenia (ed. H. Häfner, W. F. Gattaz and W. Janzarik), pp. 107-113. Springer-Verlag: Berlin.

World Health Organization (1973). The International Pilot Study of Schizophrenia. Volume 1. WHO: Geneva.

World Health Organization (1979). Schizophrenia: an International Follow-up Study. John Wiley: Chichester. 